\title{
STRUCTURAL DETERMINATION OF EPITAXIAL FORMATIONS IN LAYERED CUPRATES
}

\author{
L. Leonyuk, V. Maltsev \\ Moscow State University, 119899 Moscow, Russia \\ AND G.-J. BABONAS \\ Semiconductor Physics Institute, 2600 Vilnius, Lithuania
}

\begin{abstract}
The fragment approximation is used for the description of the layered cuprate structures. The characteristic structural features are distinguished which genetically relate all the layered cuprates. The classification scheme for the whole family of layered cuprates is analyzed in the fragment approximation and a possible extension of the scheme is discussed.
\end{abstract}

PACS numbers: 74.62.Bf, 74.72.-h

From the discovery of high- $T_{\mathrm{c}}$ superconductors the layered cuprates were carefully analyzed in order to reveal the correlation between the structure and physical properties. Basing on the experimental observations, the temperature of the transition to superconducting state has been correlated with the number of $\mathrm{Cu}-\mathrm{O}$ planes and with particular interatomic distances, hence emphasizing the role of crystalline structure.

Due to the growth problems of thin films and heteroepitaxial layers, a further attention was paid to the study of commonalities and differences between superconducting compounds of various compositions and co-crystallizing phases. As a result, various classification schemes have been developed in order to reveal the general regularities in the structure for the whole group of cuprates.

The aim of the present paper was to analyze the genetic relationship between the structures of various layered cuprates, to which the major part of high- $T_{\mathrm{c}}$ superconductors is attributed. It will be shown that from the viewpoint of the structural regularities, the formation of epitaxial intergrowths is not only typical but a predetermined feature for the family of these compounds.

Previous classification schemes of cuprate structures [1-3] distinguished the following main features: (i) the layered character of structure; (ii) the presence of copper-oxygen fragments, containing single $\mathrm{Cu}-\mathrm{O}$ plane or doubled $\mathrm{Cu}-\mathrm{O}$ planes with cation layer between them; (iii) the existence of blocking layers of rock-saltand fluorite-type which are located between the $\mathrm{Cu}-\mathrm{O}$ fragments; (iv) a similarity of cuprate structure to the perovskite. 
The present analysis was also based on the selection of the characteristic structural features. The structures of layered cuprates were treated as a regular stacking of the layered fragments along the $c$-axis. However, in contrast to previous schemes, the basic structural units of layered cuprates were distinguished by the crystal chemistry argumentation and represented by the structural fragments of real compounds.

Using the methods of crystal chemistry, two general features, stability and variability of the structures, are usually considered. In the fragment approximation [4] it is assumed that the structural unit, the minal, can be distinguished in a series of compounds. The minal is a constant unit in the group of related structures and hence contains the features common for the whole series of compounds. As a volume structural unit, the minal is able to reproduce itself or to be transported, as a complete constant unit, when passing from one compound to another in the series under consideration.

On the other hand, the minal is able to be transformed. This minal feature corresponds to the variability of the structural types in the family of related compounds. The complexity and size of minal depend on the number of common features of the compounds under consideration. The greater is the common factor of various structures, the less complicated is the minal. The parameters of the unit cells in the basal plane are nearly identical in layered cuprates. Therefore, the constructive-minal approximation seems to be particularly effective. All the changes in the structures of layered cuprates manifest themselves in the character of stacking of layered fragments along the $c$-axis. As the sizes of various fragments are nearly constant, hence the parameters of unit cells can be easily estimated.

The family of layered cuprates consists of compounds which contain the $\mathrm{Cu}-\mathrm{O}$ layers. Therefore, the $\mathrm{Cu}-\mathrm{O}$ arrangement predetermines the structure, in spite of the fact that all layered cuprates are assigned to the complex oxides containing one or more cations in addition to $\mathrm{Cu}$.

We have distinguished three main minals in the structures of layered cuprates (Fig. 1). The minal $M_{1}$ is originated from the parent structure $\mathrm{La}_{2} \mathrm{CuO}_{4}(T$-type)

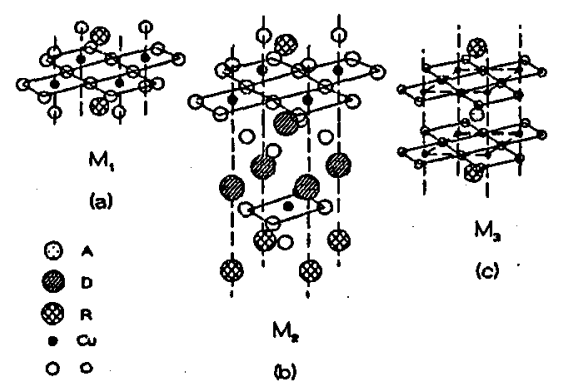

Fig. 1. Structures of main minals $M_{1}$ (a), $M_{2}$ (b) and $M_{3}$ (c) in layered cuprates. $\mathrm{R}=$ $\mathrm{Ba}, \mathrm{Sr}$, rare earth $(\mathrm{RE}), \mathrm{D}=\mathrm{Ce}+\mathrm{RE}, \mathrm{Pr}+\mathrm{RE} ; \mathrm{A}=\mathrm{Ca}, \mathrm{Y}$, less often La $+\mathrm{Sr} ; \mathrm{RO}$ and $\mathrm{D}_{2} \mathrm{O}_{2}$ represent correspondingly the layers containing cations and oxygen atoms in one plane ("NaCl-type") or in different planes ("CaF 2 -type") stacked along the $c$-axis. 
and it consists of $\mathrm{CuO}_{2}$-plane between two atomic layers of the rock-salt-type. When minals are doubled in the real structure, the layers shift one with respect to another in the $(a b)$-plane.

The parent structure for the minal $M_{2}$ is actually the $T^{\prime}$ structure $\left(\mathrm{Pr}_{2} \mathrm{CuO}_{4}\right)$. In the real structure, the minal $M_{2}$ represents the fragment of $T^{\prime \prime}$ structure, located between two atomic layers of the rock-salt-type, i.e., the structure $T^{*}$, e.g., $(\mathrm{Nd}, \mathrm{Sr}, \mathrm{Ce})_{2}(\mathrm{Nd}, \mathrm{Sr}, \mathrm{Ce})_{2} \mathrm{Cu}_{2} \mathrm{O}_{8}$.

Minal $M_{3}$ is originated from the $\mathrm{CaCuO}_{2}$-structure and represents its fragment situated between two atomic layers of the rock-salt-type. The doubled sequence of layers in $M_{3}$ is realized in the $\mathrm{La}_{2-x} \mathrm{Sr}_{1+x} \mathrm{Cu}_{2} \mathrm{O}_{6}$.

The minal $M_{3}$ can be made more complicated by inserting additional fragments of $\mathrm{CaCuO}_{2}$. In general, the sequence of minals can be developed from minal $M_{1}$ by doubling the $\mathrm{Cu}-\mathrm{O}$ layer with additional cation layer in $M_{3}$ or fluorite-like layer in $\mathrm{M}_{2}$ inserted between the $\mathrm{CuO}_{2}$-layers.

The structures of various layered cuprates can be obtained when minals are alternatingly stacked along the $c$-axis direction with several types of cation-oxygen layers. The additional layers in cuprates can be considered as the "blocking layers" with respect to $\mathrm{Cu}$-containing minals in the sequence of alternating fragments stacked along the $c$-axis.

The blocking layers can be divided into two groups. In group I $\left(L_{1}-L_{5}\right)$ the blocking layers share oxygen atoms with neighboring layers of minals, whereas in group II $\left(L_{6}, L_{7}\right)$ the minals and blocking layers can be considered as relatively isolated units. In group I two blocking layers contain $\mathrm{Cu}$ in the linear $\left(L_{1}\right)$ or in the square $\left(L_{2}\right)$ coordination. In both cases the oxygen atoms at apexes are assigned to minal layers. The blocking layers $\left(L_{4}, L_{5}\right)$ can be considered as perovskite fragment with cations (Nb, Sn, Sc, Fe, Al) in octahedral coordination, or as pseudo-perovskite oxygen-deficient fragment with cations ( $\mathrm{Ga}, \mathrm{Al}, \mathrm{Fe}$ ) in tetrahedral coordination. The doubled perovskite-like layer $\left(L_{5}\right)$ with $\mathrm{Ti}, \mathrm{Sn}$ in fact represents a complete perovskite-like structure, and it is rarely met in layered cuprates.

The essential feature of the blocking layers in the group I is the ability to form the combined layers. For example, in the structure of Y-123 compound doped by $\mathrm{Al}$ the blocking layer can be represented by the layers $L_{1}+L_{3}$ (Cu-dumb-bells and Al-tetrahedra) or $L_{2}+L_{4}$ (Cu-squares and Al-octahedra).

Group II of the blocking layers is represented by a single rock-salt-type layer $L_{6}$ or by doubled layer $L_{7}$ containing cations with relatively large radii as compared with group I.

In the scheme considered we have introduced the numerical notation scheme. In addition, the characters are added to note the presence in blocking layers of the chains of $\mathrm{Cu}$ in linear (C) and square (S) coordination as well as the chains of tetrahedra $(\mathrm{T})$ and cations in octahedral $(\mathrm{O})$ coordination. In the four-number scheme the first entry notes the number of cation or cation-oxygen layers in the blocking fragment. The other three entries characterize minal $M_{i}$. The second numeral notes the number of rock-salt-type layers $\mathrm{RO}$ outside the $\mathrm{Cu}-\mathrm{O}$ units in the minal. Third and fourth numerals characterize the Cu-containing minal 
TABLE

The scheme of the main structural types of layered cuprates with principal minals.

\begin{tabular}{c|c|c|c}
\hline \hline Blocking layers & \multicolumn{3}{|c}{ Minals } \\
\cline { 2 - 4 } & $M_{1}(0201)$ & $M_{2}(0021)$ & $M_{3}(0011)$ \\
\hline$L_{1}: \mathrm{Cu}$ & $1201-\mathrm{C}(\mathrm{a})$ & & $1212-\mathrm{C}(\mathrm{l})$ \\
$L_{2}: \mathrm{CuO}$ & & & $1212-\mathrm{S}(\mathrm{m})$, \\
& & & $2212-\mathrm{S}(\mathrm{n})$ \\
$L_{3}:(\mathrm{Al}, \mathrm{Ga}) \mathrm{O}$ & $1201-\mathrm{T}(\mathrm{b})$ & $1222-\mathrm{T}(\mathrm{g})$ & $1212-\mathrm{T}(\mathrm{o})$ \\
$L_{4}:(\mathrm{Nb}, \mathrm{Sc}) \mathrm{O}_{2}$ & $1201-\mathrm{O}(\mathrm{c})$ & $1222-\mathrm{O}(\mathrm{h})$ & $1212-\mathrm{O}(\mathrm{p})$ \\
$L_{5}: 2(\mathrm{Ti}, \mathrm{Sn}) \mathrm{O}_{2}$ & & & $3212-\mathrm{O}(\mathrm{q})$ \\
$L_{6}:(\mathrm{Tl}, \mathrm{Bi}, \mathrm{Pb}, \mathrm{Pb}+\mathrm{Cu}, \mathrm{La}+\mathrm{Sr}, \mathrm{Hg}) \mathrm{O}$ & $1201(\mathrm{~d})$ & $1222(\mathrm{i})$ & $1212(\mathrm{r})$ \\
$L_{7}: 2(\mathrm{Tl}, \mathrm{Bi}) \mathrm{O}$ & $2201(\mathrm{e})$ & $2222(\mathrm{j})$ & $2212(\mathrm{~s})$ \\
$L_{1}+L_{6}: \mathrm{Cu}+\mathrm{PbO}$ & $3201-\mathrm{C}(\mathrm{f})$ & $3222-\mathrm{C}(\mathrm{k})$ & $3212-\mathrm{C}(\mathrm{t})$ \\
\hline
\end{tabular}

Examples of structural types: $\mathrm{Cu}-12(n-1) n(\mathrm{a}) ; \mathrm{Ga}(\mathrm{La}, \mathrm{Sr})_{2} \mathrm{CuO}_{5}$ (b);

$\mathrm{ScBa}_{2} \mathrm{CuO}_{5}$ (c); $\mathrm{HgBa}_{2} \mathrm{CuO}_{5}$ (d); $\mathrm{Tl}_{2} \mathrm{Ba}_{2} \mathrm{CuO}_{6}$ (e); (Cu, $\left.\mathrm{Pb}_{2}\right)(\mathrm{Sr}, \mathrm{La})_{2} \mathrm{CuO}_{6}$ (f); $(\mathrm{Ga}, \mathrm{Cu})(\mathrm{Sr}, \mathrm{Eu})_{2}(\mathrm{Eu}, \mathrm{Ce})_{2} \mathrm{Cu}_{2} \mathrm{O}_{9}(\mathrm{~g}) ; \mathrm{Nb}(\mathrm{Pr}, \mathrm{Ce})_{2} \mathrm{Sr}_{2} \mathrm{Cu}_{2} \mathrm{O}_{10}$ (h);

$(\mathrm{Pb}, \mathrm{Cu})(\mathrm{Eu}, \mathrm{Ce})_{2}(\mathrm{Sr}, \mathrm{Eu})_{2} \mathrm{Cu}_{2} \mathrm{O}_{9}$ (i); $\mathrm{Bi}_{2} \mathrm{Sr}_{2}(\mathrm{Gd}, \mathrm{Ce})_{2} \mathrm{Cu}_{2} \mathrm{O}_{10}(\mathrm{j})$;

$\left(\mathrm{Cu}, \mathrm{Pb}_{2}\right) \mathrm{Sr}_{2}(\mathrm{R}, \mathrm{Ce})_{2} \mathrm{Cu}_{2} \mathrm{O}_{10}(\mathrm{k}) ; \mathrm{YBa}_{2} \mathrm{Cu}_{3} \mathrm{O}_{6}(\mathrm{l}) ; \mathrm{YBa}_{2} \mathrm{Cu}_{3} \mathrm{O}_{7}(\mathrm{~m})$;

$\mathrm{YBa}_{2} \mathrm{Cu}_{4} \mathrm{O}_{8}$ (n); (Y, Ca) $\mathrm{Sr}_{2} \mathrm{Cu}_{2} \mathrm{GaO}_{7}$ (o); $\mathrm{NbBa}_{2} \mathrm{LaCu}_{2} \mathrm{O}_{8}$ (p);

$\left(\mathrm{LaSn}_{2}\right) \mathrm{Ba}_{2} \mathrm{LaCu}_{2} \mathrm{O}_{11}$ (q); $\mathrm{TlBa}_{2} \mathrm{CaCu}_{2} \mathrm{O}_{7}(\mathrm{r}) ; \mathrm{Bi}_{2} \mathrm{Sr}_{2} \mathrm{CaCu}_{2} \mathrm{O}_{8}$ (s);

$\left(\mathrm{CuPb}_{2}\right) \mathrm{Sr}_{2} \mathrm{YCu}_{2} \mathrm{O}_{8}(\mathrm{t})$.

fragment. The fourth numeral is the number of $\mathrm{Cu}-\mathrm{O}$ planes, while third entry is the number of cation layers between $\mathrm{Cu}-\mathrm{O}$ planes.

A part of the classification scheme for layered cuprates can be illustrated by Table, in which the horizontal line represents the series of compounds with constant blocking layers and various minals $M_{1}-M_{3}$ and the vertical line represents the series of compounds with constant minal and various blocking layers. Each combination of minal and blocking layer symbolizes the structural type.

In conclusion, it should be noted that the classification scheme based on the fragment approximation can be applied to analyze the isomorphic substitution in layered cuprates and the corresponding structural changes. Various isomorphic substitutions are possibly to be performed in minals as the most stable structural fragments. In contrast, the substitutions of atoms in the blocking layer result usually in the change of the structural type.

\section{References}

[1] Y. Tokura, T. Arima, Jpn. J. Appl. Phys. 29, 2388 (1990).

[2] G.D. Ilyushin, L.N. Dem'yanets, Superconductivity 4, 245 (1991).

[3] R. Yoshizaki, Physica C 173, 89 (1991).

[4] N.L. Smirnova, S.D. Polzikov, N.A. Rebrova, Kristallografiya 18, 1182 (1973). 